\title{
Synergistic Activities of Fluconazole and Voriconazole with Terbinafine against Four Candida Species Determined by Checkerboard, Time-Kill, and Etest Methods
}

\author{
Emilia Cantón, ${ }^{1 *}$ Javier Pemán, ${ }^{2}$ Miguel Gobernado, ${ }^{2}$ Angel Viudes, ${ }^{2}$ \\ and Ana Espinel-Ingroff ${ }^{3}$ \\ Unidad de Microbiología Experimental-Centro de Investigación ${ }^{1}$ and Servicio de Microbiología, ${ }^{2}$ \\ Hospital Universitario La Fe, Valencia, Spain, and Division of Infectious Disease, \\ VCU Medical Center, Richmond, Virginia ${ }^{3}$
}

Received 2 September 2004/Returned for modification 8 October 2004/Accepted 18 December 2004

\begin{abstract}
The in vitro activities of fluconazole or voriconazole plus terbinafine were evaluated against 20 Candida isolates by the checkerboard, time-kill, and Etest methods. Synergism (C. albicans, C. glabrata, and C. tropicalis) and indifference $(C$. krusei) were observed. Correlation among methods was good. The Etest is a suitable method to determine drug interactions.
\end{abstract}

The checkerboard and time-kill methods to determine in vitro interactions between drugs are time-consuming and cumbersome for use in clinical laboratories. In order to find a method that facilitates synergistic studies, our aim was dual: (i) to assess the in vitro activities of voriconazole (VRC) and fluconazole (FLC) combined with terbinafine (TRB) against four Candida spp. (resistant or susceptible to FLC and/or TRB) by the checkerboard and time-kill methods and (ii) to compare the results of these methods with those obtained by an Etest-agar dilution technique.

Twenty blood isolates (Table 1) were tested. C. parapsilosis ATCC 22019 and C. krusei ATCC 6258 were included for quality control.

Stock solutions of VRC, FLC (Pfizer, Barcelona, Spain), and TRB (Novartis, Barcelona, Spain) were prepared with the appropriate solvent (dimethyl sulfoxide for VRC and TRB and distilled water for FLC). The final concentrations were 0.002 to $2 \mu \mathrm{g} / \mathrm{ml}$ for VRC, 0.06 to $64 \mu \mathrm{g} / \mathrm{ml}$ for FLC, and 0.25 to 16 $\mu \mathrm{g} / \mathrm{ml}$ for TRB. MICs of drugs alone or in combination were determined by the NCCLS M27-A2 method (12) and corresponded to the lowest concentration that showed prominent $(\geq 50 \%)$ growth inhibition and by the Etest method as described below.

Drug interactions were assessed by the following three methods described below: broth microdilution checkerboard, timekill, and Etest.

(i) Broth microdilution checkerboard. The broth microdilution checkerboard method was performed by using the fractional inhibitory concentration (FIC) index, which is defined as the sum of the MIC of each drug when used in combination divided by the MIC of the drug when used alone. For computation of FIC indices, off-scale MICs were raised to the next highest MIC; synergistic and antagonistic FIC indices were defined as $\leq 0.5$ and $>4$, respectively.

\footnotetext{
* Corresponding author. Mailing address: Unidad de Microbiología Experimental, Centro de Investigación, Hospital Universitario La Fe, Avenida Campanar 21, 46009 Valencia, Spain. Phone: 34961973111. Fax: 3496 1973018. E-mail: canton_emi@gva.es.
}

(ii) Time-kill studies. One isolate of each species was selected, and tests were conducted as previously described (RPMI 1640 medium, 105 -CFU/ml inoculum, and 5-ml volume) (8). The drug concentrations tested alone were as follows: VRC, 16 and $1 \mu \mathrm{g} / \mathrm{ml}$; FLC, 32 and $2 \mu \mathrm{g} / \mathrm{ml}$; and TRB, 8 and $2 \mu \mathrm{g} / \mathrm{ml}$. For the combinationsVRC/TRB and FLC/TRB, the drug concentrations were as follows: VRC/TRB, 16/2, 1/2, and $1 / 8 \mu \mathrm{g} / \mathrm{ml}$; and FLC/TRB, 32/2, 32/8, 2/2, and 2/8 $\mu \mathrm{g} / \mathrm{ml}$. At $0,3,6,24$, and $48 \mathrm{~h}$, aliquots were removed to determine the number of CFU per milliliter. Synergy was defined as a $\geq 2$ $\log _{10}$ decrease in CFU per milliliter for a combination compared to the killing with the most active drug alone and an increase of $\geq 2 \log _{10}$ as antagonism. Experiments were conducted in duplicate and on 2 separate days.

(iii) Etest studies. RPMI 1640 agar with 2\% dextrose and 1, 2 , and $8 \mu \mathrm{g}$ of TRB per $\mathrm{ml}$, prepared as described elsewhere (7), was used. For each strain, FLC or VRC Etest strips were applied to two agar plates, one with TRB (MIC of the combination) and another without it (azole MIC). Plates were inoculated following the manufacturer's instructions; MICs were obtained at 24 and $48 \mathrm{~h}$. An azole MIC reduction of $\geq 3$ dilutions in the presence of TRB was defined as synergy, and an increase of $\geq 3$ dilutions was defined as antagonism.

MICs for the quality control strains were within the acceptable range $(6,12)$. Although 24-h Etest MICs were within 2 dilutions compared with those obtained by M27-A2 (48 h) for most isolates, the M27-A2 method detected resistance while Etest provided susceptible results for some $C$. tropicalis isolates (Tables 1 to 3 ); however, Etest ellipses had heavy trailing growth.

By checkerboard, the combination of both azoles and TRB was synergistic against four strains each of C. albicans, C. glabrata, and $C$. tropicalis ( FIC index, $\leq 0.5$ ) (Table 1). Against C. albicans, MICs of FLC and VRC were 0.06 and 0.002 to 0.03 $\mu \mathrm{g} / \mathrm{ml}$, respectively, when combined with 0.25 to $0.5 \mu \mathrm{g}$ of TRB per ml. Both azoles in combination with TRB inhibited the growth of $C$. albicans. Against $C$. glabrata, FLC MICs decreased to 1 to $4 \mu \mathrm{g} / \mathrm{ml}$ upon combination with 0.5 to $2 \mu \mathrm{g}$ of TRB per ml. VRC MICs decreased 2 to 3 dilutions when 
TABLE 1. In vitro interaction between FLC and TRB and between VRC and TRB by the checkerboard method

\begin{tabular}{|c|c|c|c|c|c|c|c|c|}
\hline \multirow{2}{*}{ Isolate } & \multicolumn{3}{|c|}{$\mathrm{MIC}(\mu \mathrm{g} / \mathrm{ml})$} & \multirow{2}{*}{$\begin{array}{l}\text { Lowest } \Sigma \text { FIC for FLC/TRB } \\
\quad(\text { interpretation })^{a}\end{array}$} & \multicolumn{3}{|c|}{ MIC $(\mu \mathrm{g} / \mathrm{ml})$} & \multirow{2}{*}{$\begin{array}{l}\text { Lowest } \Sigma \text { FIC for VRC/TRB } \\
\text { (interpretation) }^{a}\end{array}$} \\
\hline & FLC & TRB & FLC/TRB & & VRC & TRB & VRC/TRB & \\
\hline \multicolumn{9}{|l|}{ C. albicans } \\
\hline EU-62 & $>64$ & 16 & $0.06 / 0.25$ & $0.016(\mathrm{~S})$ & $>2$ & $>16$ & $0.002 / 0.5$ & $0.016(\mathrm{~S})$ \\
\hline EU-78 & 1 & 0.25 & $0.06 / 0.25$ & 1.12 (I) & 0.008 & 0.5 & $0.004 / 0.25$ & 1.00 (I) \\
\hline EU-80 & $>64$ & $>16$ & $0.06 / 0.5$ & $0.016(\mathrm{~S})$ & $>2$ & $>16$ & $0.002 / 0.5$ & 0.016 (S) \\
\hline EU-87 & 64 & 16 & $0.06 / 0.25$ & 0.016 (S) & $>2$ & $>16$ & $0.002 / 0.5$ & 0.016 (S) \\
\hline EU-170 & 2 & $>16$ & $0.06 / 0.5$ & $0.054(\mathrm{~S})$ & $>2$ & 8 & $0.03 / 0.5$ & $0.07(\mathrm{~S})$ \\
\hline \multicolumn{9}{|l|}{ C. glabrata } \\
\hline EU-12 & $>64$ & $>16$ & $4 / 0.5$ & $0.046(\mathrm{~S})$ & $>2$ & $>16$ & $0.5 / 0.25$ & $0.132(\mathrm{~S})$ \\
\hline EU-38 & 16 & $>16$ & $32 / 4$ & 2.125 (I) & $>2$ & $>16$ & $1 / 4$ & 0.375 (S) \\
\hline EU-68 & 8 & $>16$ & $1 / 1$ & 0.156 (S) & $>2$ & $>16$ & $1 / 4$ & 0.375 (S) \\
\hline EU-151 & 32 & $>16$ & $1 / 2$ & 0.093 (S) & 0.5 & $>16$ & $0.5 / 0.25$ & 1.007 (I) \\
\hline EU-195 & 16 & $>16$ & $4 / 2$ & $0.312(\mathrm{~S})$ & $>2$ & $>16$ & $0.25 / 2$ & 0.125 (S) \\
\hline \multicolumn{9}{|l|}{ C. tropicalis } \\
\hline EU-43 & $>64$ & $>16$ & $1 / 0.5$ & $0.023(\mathrm{~S})$ & 0.12 & $>16$ & $0.002 / 8$ & $0.266(\mathrm{~S})$ \\
\hline EU-240 & $>64$ & $>16$ & $16 / 2$ & 0.187 (S) & $>2$ & $>16$ & $0.25 / 2$ & 0.125 (S) \\
\hline EU-245 & $>64$ & $>16$ & $0.5 / 0.25$ & $0.0117(\mathrm{~S})$ & 1 & $>16$ & $0.03 / 8$ & 0.282 (S) \\
\hline EU-255 & $>64$ & 16 & $1 / 0.5$ & $0.023(\mathrm{~S})$ & $>2$ & $>16$ & $0.016 / 8$ & 0.254 (S) \\
\hline EU-264 & 1 & $>16$ & $0.5 / 0.25$ & 0.5078 (I) & 0.03 & $>16$ & $0.016 / 0.25$ & 0.5078 (I) \\
\hline \multicolumn{9}{|l|}{ C. krusei } \\
\hline EU-123 & 64 & $>16$ & $64 / 0.25$ & $1.0078(\mathrm{I})$ & 0.5 & $>16$ & $0.5 / 0.25$ & $1.0078(\mathrm{I})$ \\
\hline CK-1 & 64 & $>16$ & $64 / 0.25$ & $1.0078(\mathrm{I})$ & 0.5 & $>16$ & $0.25 / 0.25$ & 0.5078 (I) \\
\hline CK-2 & $>64$ & $>16$ & $64 / 16$ & 1 (I) & 1 & $>16$ & $0.25 / 0.25$ & 0.2578 (S) \\
\hline CK-3 & 64 & $>16$ & $64 / 0.25$ & $1.0078(\mathrm{I})$ & 0.5 & $>16$ & $0.25 / 0.25$ & $0.5078(\mathrm{I})$ \\
\hline CK-4 & 64 & $>16$ & $64 / 0.25$ & 1.0078 (I) & 0.5 & $>16$ & $0.5 / 0.25$ & 1.0078 (I) \\
\hline
\end{tabular}

${ }^{a} \mathrm{~S}$, synergism; I, indifference.

combined with $\geq 0.5 \mu \mathrm{g}$ of TRB per ml, and TRB MICs were reduced to 0.25 to $4 \mu \mathrm{g} / \mathrm{ml}$ in the presence of $\geq 0.25 \mu \mathrm{g}$ of VRC per ml (Table 1). MICs of FLC for C. tropicalis were $\leq 1 \mu \mathrm{g} / \mathrm{ml}$ combined with TRB $(\geq 0.25 \mu \mathrm{g} / \mathrm{ml})$, except for one strain, for which the FLC MIC was $16 \mu \mathrm{g} / \mathrm{ml}$ in presence of $2 \mu \mathrm{g}$ of TRB per ml. VRC MICs were $\leq 0.25 \mu \mathrm{g} / \mathrm{ml}$ when combined with $\geq 2 \mu \mathrm{g}$ of TRB per ml. Against C. krusei, the interaction of both azoles with TRB was indifferent for four strains ( $\Sigma$ FIC

TABLE 2. Effect of TRB concentration on FLC activity as determined by the checkerboard and Etest methods

\begin{tabular}{|c|c|c|c|c|c|c|c|c|}
\hline \multirow{3}{*}{ Strain } & \multicolumn{8}{|c|}{ FLC MIC $(\mu \mathrm{g} / \mathrm{ml})$ with TRB concn of ${ }^{a}$ : } \\
\hline & \multicolumn{2}{|c|}{0} & \multicolumn{2}{|c|}{$1 \mu \mathrm{g} / \mathrm{ml}$} & \multicolumn{2}{|c|}{$2 \mu \mathrm{g} / \mathrm{ml}$} & \multicolumn{2}{|c|}{$8 \mu \mathrm{g} / \mathrm{ml}$} \\
\hline & M27-A2 & Etest & Checkerboard & Etest & Checkerboard & Etest & Checkerboard & Etest \\
\hline \multicolumn{9}{|l|}{ C. albicans } \\
\hline EU-62 & $>64$ & 64 & $<0.06-1 *$ & $0.016 *$ & $0.06-1 *$ & $0.06 *$ & $0.06-1 *$ & $0.12 *$ \\
\hline EU-78 & 1 & 0.25 & $<0.06$ & $2^{*}$ & $0.06-1 *$ & $0.12 *$ & $0.06-1 *$ & $0.06 *$ \\
\hline EU-80 & $>64$ & $>256$ & $<0.06$ & 0.5 & $0.06-1 *$ & $0.25 *$ & $0.06-1 *$ & $1.5 *$ \\
\hline EU-87 & 64 & 64 & $<0.06$ & 0.5 & $0.06-1 *$ & $0.25 *$ & $0.06-1 *$ & $0.38 *$ \\
\hline EU-170 & 2 & 0.5 & $<0.06$ & 0.75 & 0.06 & $0.25 *$ & $0.06-1 *$ & $0.38 *$ \\
\hline \multicolumn{9}{|l|}{ C. glabrata } \\
\hline EU-12 & $>64$ & $>256$ & 4 & $\mathrm{ND}^{b}$ & 4 & 1 & 1 & 0.5 \\
\hline EU-38 & 16 & 24 & 64 & ND & 64 & 32 & 32 & 16 \\
\hline EU-68 & 8 & 16 & 8 & ND & 8 & 8 & 0.5 & 8 \\
\hline EU-151 & 32 & 32 & 8 & ND & 1 & 8 & 1 & 8 \\
\hline EU-195 & 16 & 16 & 8 & ND & 4 & 16 & 4 & 2 \\
\hline \multicolumn{9}{|l|}{ C. tropicalis } \\
\hline EU-43 & $>64$ & 1 & 1 & ND & 1 & 1 & 0.5 & 1 \\
\hline EU-240 & $>64$ & 12 & 32 & ND & 16 & 12 & 16 & 12 \\
\hline EU-245 & $>64$ & 0.5 & 0.5 & ND & 0.5 & 0.38 & 0.12 & 0.38 \\
\hline EU-255 & $>64$ & 0.75 & 1 & ND & 1 & 2 & $<0.06$ & 2 \\
\hline EU-264 & 1 & 1 & 0.5 & ND & 0.5 & 1 & 0.5 & 1 \\
\hline \multicolumn{9}{|l|}{ C. krusei } \\
\hline EU-123 & 64 & 64 & 64 & ND & 64 & 32 & 64 & 32 \\
\hline CK-1 & 64 & 64 & 64 & ND & 64 & 64 & 64 & 32 \\
\hline CK-2 & $>64$ & $>64$ & $>64$ & ND & $>64$ & 128 & $>64$ & 64 \\
\hline CK-3 & 64 & 64 & 64 & ND & 64 & 48 & 64 & 48 \\
\hline CK-4 & 64 & $>256$ & 64 & ND & 64 & 48 & 64 & 64 \\
\hline
\end{tabular}

${ }^{a}$ Asterisks indicate the minimum drug concentration that produced $100 \%$ growth inhibition.

${ }^{b} \mathrm{ND}$, not determined. 
TABLE 3. Effect of TRB concentration on VRC activity as determined by the checkerboard and Etest methods

\begin{tabular}{|c|c|c|c|c|c|c|c|c|}
\hline \multirow{3}{*}{ Strain } & \multicolumn{8}{|c|}{ VRC MIC $(\mu \mathrm{g} / \mathrm{ml})$ with TRB concn of: } \\
\hline & \multicolumn{2}{|c|}{0} & \multicolumn{2}{|c|}{$1 \mu \mathrm{g} / \mathrm{ml}$} & \multicolumn{2}{|c|}{$2 \mu \mathrm{g} / \mathrm{ml}$} & \multicolumn{2}{|c|}{$8 \mu \mathrm{g} / \mathrm{ml}$} \\
\hline & M27-A2 & Etest & Checkerboard & Etest & Checkerboard & Etest & Checkerboard & Etest \\
\hline \multicolumn{9}{|l|}{ C. albicans } \\
\hline EU-62 & $>2$ & $>32$ & 0.002 & 0.002 & $0.03 *$ & $0.004 *$ & $0.002 *$ & $0.008 *$ \\
\hline EU-78 & 0.008 & 0.008 & $0.002 *$ & $0.008 *$ & $0.002 *$ & $0.004 *$ & $0.002 *$ & $0.008 *$ \\
\hline EU-80 & $>2$ & $>32$ & $0.002-0.06 *$ & 0.002 & $0.002 *$ & $0.002 *$ & $0.002 *$ & $0.016 *$ \\
\hline EU-87 & $>2$ & $>32$ & $0.002 *$ & $0.016 *$ & $0.002 *$ & $0.016 *$ & $0.002 *$ & $0.012 *$ \\
\hline EU-170 & $>2$ & $>32$ & 0.016 & 0.016 & $0.03 *$ & $0.012 *$ & $0.002 *$ & $0.012 *$ \\
\hline \multicolumn{9}{|l|}{ C. glabrata } \\
\hline EU-12 & $>2$ & $>32$ & 0.5 & $\mathrm{ND}^{b}$ & 0.12 & 0.5 & 0.12 & 0.5 \\
\hline EU-38 & $>2$ & 16 & $>2$ & ND & $>2$ & 0.5 & 1 & 0.5 \\
\hline EU-68 & $>2$ & 8 & 2 & ND & 2 & 8 & 1 & 2 \\
\hline EU-151 & 0.5 & 2 & 2 & ND & 2 & 1 & 0.5 & 0.25 \\
\hline EU-195 & $>2$ & 0.5 & 0.5 & ND & 0.25 & 0.38 & 0.12 & 0.12 \\
\hline \multicolumn{9}{|l|}{ C. tropicalis } \\
\hline EU-43 & 0.12 & 0.06 & 2 & ND & 0.25 & 0.12 & 0.002 & 0.12 \\
\hline EU-240 & $>2$ & 0.19 & $>2$ & ND & 0.25 & 0.38 & 0.25 & 0.5 \\
\hline EU-245 & 1 & 0.06 & 0.12 & ND & 0.12 & 0.12 & 0.016 & 0.047 \\
\hline EU-255 & $>2$ & 0.25 & $>2$ & ND & 2 & 0.25 & 0.016 & 0.5 \\
\hline EU-264 & 0.03 & 0.12 & 0.016 & ND & 0.016 & 0.06 & 0.016 & $0.19 *$ \\
\hline \multicolumn{9}{|l|}{ C. krusei } \\
\hline EU-123 & 0.5 & 0.25 & 0.5 & ND & 0.5 & $0.19 *$ & $0.5 *$ & $0.25 *$ \\
\hline CK-1 & 0.5 & 0.25 & 0.25 & ND & 0.25 & $0.25 *$ & $0.25 *$ & $0.12 *$ \\
\hline CK-2 & 1 & 0.5 & 0.5 & ND & 0.5 & $0.5 *$ & $0.5 *$ & $0.5 *$ \\
\hline CK-3 & 0.5 & 0.25 & 0.25 & ND & 0.25 & $0.25 *$ & $0.25 *$ & $0.25 *$ \\
\hline CK-4 & 0.5 & 0.25 & 0.5 & ND & 0.5 & $0.25 *$ & $0.5 *$ & $0.25 *$ \\
\hline
\end{tabular}

${ }^{a}$ Asterisks indicate the minimum drug concentration that produced $100 \%$ growth inhibition.
${ }^{b} \mathrm{ND}$, not determined.

index, 0.5078 to 1.01$)$, while the combination VRC/TRB was synergistic $(\Sigma$ FIC index $=0.2578)$ for one isolate $(\mathrm{Ta}-$ ble 1).

By the time-kill method, the combination of both azoles with TRB was indifferent: none of the killing curves showed more than a $1.5-\log$ decrease in killing in either of the two independent tests made (data not shown).

Tables 2 and 3 depict the interaction of azoles with TRB by Etest. In general, Etest synergistic results were in agreement with those obtained by the checkerboard method with the same concentrations of TRB.

Our results by the checkerboard method confirm previous reports $(4,5,14,19)$ and extend them to $C$. tropicalis and C. krusei. We found that the combination of FLC or VRC with TRB was synergistic for $C$. albicans, $C$. glabrata (strain dependent), and $C$. tropicalis and indifferent for $C$. krusei by the checkerboard and Etest methods. However, by the time-kill method, the interaction was indifferent. The lowest FIC indices for the combination of both azoles and TRB were obtained at achievable concentrations in serum of $3.6 \mu \mathrm{g} / \mathrm{ml}$ for TRB (3, $11,18), 30 \mu \mathrm{g} / \mathrm{ml}$ for $\operatorname{FLC}(9,17,18)$, and up to $5.2 \mu \mathrm{g} / \mathrm{ml}$ for $\operatorname{VRC}(2,10,16)$. The three methods showed good correlation for most of the species, although by the checkerboard method, the synergistic effect was stronger. The lack of agreement between the checkerboard and Etest methods for $C$. tropicalis could be due to the heavy trailing growth observed at $48 \mathrm{~h}$ by the microdilution method; agreement was good with 24-h MICs by the latter method. To our knowledge, there are no other reports describing the same drug combinations, species, and methods. It is interesting that when the TRB concentration that produced the interaction with the azole was reached, a further increase did not decrease the azole MIC. This was demonstrated by the three methods.

By using available Etest strips and incorporating subinhibitory concentrations of TRB into the RPMI agar, we were able to determine interactions between these agents. These results were similar to those obtained by the most frequently used checkerboard method (Tables 2 and 3). The Etest could be a suitable method in clinical laboratories, because both RPMI agar and Etest strips are commercially available for established agents. In addition, the incorporation of the new agent into the agar plate can be made by flooding the agar plate with the appropriate drug concentrations as recommended in the NCCLS M44-P document (13). Our methodology could also be useful to study the interaction of antifungal agents with other substances (antineoplasic, anti-inflammatory, immunosuppressive drugs, etc.) $(1,15)$. Further studies are needed to determine reliability of these methods and the correlation of in vitro and in vivo results.

We thank Pfizer Laboratories for financial support for Isabel Moreno, who performed the synergy testing.

\section{REFERENCES}

1. Afeltra, J., J. F. G. Meis, R. G. Vitale, J. W. Mouton, P. E. Verweij, and the Eurofung Network. 2002. In vitro activities of pentamidine, trimethoprim, and sulfonamides against Aspergillus species. Antimicrob. Agents Chemother. 46:2029-2031.

2. Andes, D., K. Marchillo, T. Stamstad, and R. Conklin. 2003. In vivo pharmacokinetics and pharmacodynamics of a new triazole, voriconazole, in a murine candidiasis model. Antimicrob. Agents Chemother. 47:3165-3169.

3. Balfour, J. A., and D. Faulds. 1992. Terbinafine. A review of its pharmacokinetic properties, and therapeutic potential in superficial mycosis. Drugs 43:259-284.

4. Barchiesi, F., L. Falconi Di Francesco, and G. Scalise. 1997. In vitro activities of terbinafine in combination with fluconazole and itraconazole against 
isolates of Candida albicans with reduced susceptibility to azoles. Antimicrob. Agents Chemother. 41:1812-1814.

5. Barchiesi, F., L. Falconi Di Francesco, P. Compagnucci, D. Arzeni, A. Giacometti, and G. Scalise. 1998. In-vitro interaction of terbinafine with amphotericin B, fluconazole and itraconazole against clinical isolates of Candida albicans. J. Antimicrob. Chemother. 41:59-65.

6. Barry, A. L., M. A. Pfaller, S. D. Brown, et al. 2000. Quality control limits for broth microdilution susceptibility tests of ten antifungal agents. J. Clin. Microbiol. 38:3457-3459.

7. Cantón, E., J. Pemán, M. Romero, and M. Gobernado. 2004. Utilidad del E-test y sus condiciones de ensayo en el estudio de la interacción de los antifúngicos. Estudio piloto. Rev. Esp. Quimioterap. 17:48-56.

8. Cantón, E., J. Pemán, M. Gobernado, A. Viudes, and A. Espinel-Ingroff. 2004. Killing kinetics patterns of amphotericin B against seven Candida species. Antimicrob. Agents Chemother. 48:2477-2482.

9. Grant, S. M., and S. P. Clissold. 1990. Fluconazole. A review of its pharmacodynamic and pharmacokinetic properties, and therapeutic potential in superficial and systemic mycoses. Drugs 39:877-916.

10. Hoffman, H. L., and R. C. Rathbun. 2002. Review of the safety and efficacy of voriconazole. Expert Opin. Investig. Drugs 11:409-429.

11. Kovarik, J. M., E. A. Mueller, H. Zehender, J. Denouel, H. Caplain, and L. Millerioux. 1995. Multiple-dose pharmacokinetics and distribution in tissue of terbinafine and metabolites. Antimicrob. Agents Chemother. 39:27382741.

12. National Committee for Clinical Laboratory Standards. 2002. Reference method for broth dilution antifungal susceptibility testing of yeasts. Approved standard, 2nd ed. NCCLS document M27-A2. National Committee for Clinical Laboratory Standards, Wayne, $\mathrm{Pa}$.
13. National Committee for Clinical Laboratory Standards. 2004. Method for antifungal disk diffusion susceptibility testing of yeasts. Approved guideline. NCCLS document M44-A. National Committee for Clinical Laboratory Standards, Wayne, $\mathrm{Pa}$

14. Perea, S., G. Gonzalez, A. W. Fothergill, D. A. Sutton, and M. G. Rinaldi. 2002. In vitro activities of terbinafine in combination with fluconazole, itraconazole, voriconazole, and posaconazole against clinical isolates of Candida glabrata with decreased susceptibility to azoles. J. Clin. Microbiol. 40:18311833.

15. Pina-Vaz, C., F. Sansonetty, A. G. Rodríguez, J. Martinez-De-Oliveira, A. F. Fonseca, and P. A. Mardh. 2000. Antifungal activity of ibuprofen alone and in combination with fluconazole against Candida species. J. Med. Microbiol. 49:831-840.

16. Purkins, L., N. Wood, P. Ghahramani, K. Greenhalgh, M. J. Allen, and D. Kleinermans. 2002. Pharmacokinetics and safety of voriconazole following intravenous- to oral-dose escalation regimens. Antimicrob. Agents Chemother. 46:2546-2553.

17. Silling, G. 2002. Fluconazole: optimized antifungal therapy based on pharmacokinetics. Mycoses 45(Suppl. 3):39-41.

18. Sorensen, K. N., R. A. Sobel, K. V. Clemons, L. Calderon, K. J. Howell, P. R. Irani, D. Pappagianis, P. L. Williams, and D. A. Stevens. 2000. Comparative efficacies of terbinafine and fluconazole in treatment of experimental coccidioidal meningitis in a rabbit model. Antimicrob. Agents Chemother. 44: 3087-3091.

19. Weig, M., and F. M. Muller. 2001. Synergism of voriconazole and terbinafine against Candida albicans isolates from human immunodeficiency virus-infected patients with oropharyngeal candidiasis. Antimicrob. Agents Chemother. 45:966-968. 